\title{
The Career Goals of Female Science Students in Canada
}

\author{
N. NEVITTE* ${ }^{*}$, R. GIBBINS $\dagger$, and P.W. CODDING $\ddagger$
}

\begin{abstract}
There are relatively few women in the Canadian scientific community and most of the available research explains this fact in terms of girls' low enrolment in high school science programmes. The research presented here suggests that the substantial seepage of women from science at a later decision-point also contributes to the lack of women in the science professions. The career goals of a matched sample of male and female senior science undergraduates at nine Canadian universities $(N=204)$ are examined. The data show (1) that there are substantial gender discrepancies in the defection rates and career aspirations of male and female science undergraduates; (2) that father's occupation emerges as a relevant background variable distinguishing female science students from their male counterparts; and (3) academic performance affects the defection rate of women from science-the top performers are more likely than average performers to defect from science. These findings are related to cross-national data and strategies for further research are suggested.
\end{abstract}

\section{RÉSUMÉ}

Il y a relativement peu de femmes au sein de la communauté scientifique du Canada et la plupart des recherches qui ont été faites à ce sujet montrent que ceci résulte de la faible proportion de jeunes filles inscrites dans les programmes de sciences des écoles secondaires. Notre recherche nous permet de penser que nous perdons un grand nombre de nos effectifs féminins beaucoup plus tard, et que ce facteur vient encore renforcer le manque flagrant de femmes exerçant une profession scientifique. Nous étudions ici les objectifs professonnels d'un échantillon équivalent de jeunes gens et de jeunes filles en dernière année de sciences dans neuf universités canadiennnes $(N=204)$. Les données recueillies montrent 1) qu'il y a une grande différence dans le taux d'abandon des hommes et des femmes, et aussi dans leurs aspirations professionnelles; 2) que la profession du père semble être un facteur déterminant, et qui distingue les étudiantes des

*Department of Political Science, University of Windsor $\nmid$ Department of Political Science, University of Calgary $\ddagger$ Department of Chemistry, University of Calgary 
étudiants; et 3) que les résultats qu'une femme obtient influent sur sa décision d'abandonner les sciences: en effect, les femmes qui obtiennent les meilleurs résultats abandonnent plus souvent que celles qui obtiennent des résultats moyens. Nous comparons ensuite ces conclusions aux autres données disponibles partout au pays et nous suggérons un plan d'étude qui permettra de pousser plus loin nos recherches.

\section{INTRODUCTION}

The observation that there are few women career scientists in Western industrialized countries is now a commonplace one. Most of the systematic evidence brought in support of the case is drawn from Britain, the United States, France and Sweden but there is little reason to suspect that Canada departs markedly from this trend. An analysis based on 1976 census data establishes the general point; it indicates that the percentage of women candidates who received degrees in engineering, mathematics and the physical sciences was too small to be measurable (Devereaux and Rechnitzer, 1980).

Admittedly, the ratio of women to men in the scientific community has probably improved marginally in the last twenty-five years. For example, in 1960-61 women made up to 0.9 percent of the full-time university teachers in engineering and applied sciences and by 1980-81 their proportion had crept up to 1.3 percent of the full-time teaching staff. Similarly, in 1960-61, 3.9 percent of all full-time university teachers of mathematics and applied sciences were women; that increased to 4.7 percent by 1980-81 (Symmons and Page, 1984).

These incremental shifts in the gender composition of the academic scientific community have been mirrored by similar changes in the non academic scientific professions over roughly the same period. (1) What has changed far more dramatically though is the increased awareness of the broader significance of the issue. The matter was succinctly put at a 1980 workshop on the science education of women where it was argued that the gender discrepancy in science education has "profound economic and political consequences in a world where the impact of science and technology is becoming increasingly significant." (Proceedings, 1982, pp. 7-8). It is the realization that such discrepancies engage broad issues of gender equality as well as questions related to the potential loss of scientific talent that has added urgency to researchers' efforts to seek out explanations for why so few Canadian women pursue scientific careers.

Where the evidence indicating the small size of the female scientific community is hardly controversial at all, the prevailing explanations for such a gender gap continue to hover in the realm of speculation. Indeed, the only firm conclusion that can be drawn from the relatively sketchy research literature is that there is no single compelling line of explanation. Three general lines of reasoning are deployed to explain why there are so few women scientists.

First, there is the argument that there are motivational differences between boys 
and girls; young males are more highly motivated than their female counterparts to pursue science subjects in school. Essentially, the motivational explanation places emphasis on the voluntaristic dimension of behaviour. If motivations are seen as the springboard of preferences then it is but a short inferential step to arrive at the conclusion that gender discrepancies in enrolment in various fields of educational endeavour represent an indirect measure of gender differences in motivations. In this respect the available Canadian data seem to match the findings in a number of other Western industrial societies. In general, girls have a lower enrolment in science than boys in high school and within the science curricula boys massively outnumber girls in the hard sciences such as math, physics and chemistry. Only in biology do girls match or outnumber their male counterparts (Scott, 1981, pp. 23-29). Some researchers, however, are not persuaded that differences in enrolments are a true measure of gender differences in science motivation. In this vein, Steinkamp and Maehr's recent comprehensive U.S. study (1984) represents one impressive attempt to assess directly science motivations. They reached two significant conclusions: First, they found gender differences in motivational orientations at the elementary and secondary school levels to be very small and they reason that such differences, by themselves, cannot be a primary explanation for females underrepresentation in science professions (1984, pp. 39-59). Second, they also found that gender differences in motivational orientations towards science tend to decrease with age (1984, pp. 49-50). What is problematic, of course, is that it is difficult for any students, females included, to return to science even though their motivation to pursue science increases as they move through the life-cycle. Perhaps more so than in other disciplines, science education is cumulative in nature - participation in advanced science depends upon earlier grounding in science. Consequently, the high proportion of "seepage" of females away from basic science training at an early stage in school careers results in a substantial permanent loss to the potential pool of female scientific talent.

A second line of reasoning looks to biological differences between males and females. This avenue of speculation, one that was popular in the 1970s, hypothesizes that there are biologically inherited gender differences in quantitative ability, visual-spatial ability and field articulation - all areas that are regarded as the essential tools of "scientific thinking" (For example, Hyde, 1981, pp. 892-901; Kelly, 1982,pp. 497-500; Maccoby and Jacklin, 1974, and Struik and Flexer, 1984, pp. 236-242). The plausibility of the biological explanation, however, has been seriously challenged on several fronts. First, the evidence supporting the biological hypothesis is, at best, very weak; at worst, it is contradictory. As Kimbell has pointed out (1982, pp. 42-59), even if the data are read very generously, the amount of gender related variance which could be explained by biological inheritance, as with the motivational hypothesis, is too small to account for the relative underrepresentaton of females in science. But beyond that, controversy revolves around the interpretation of the data. Is it possible to separate causes from symptoms? To put the matter differently, can the 
apparent gender differences in scientific aptitudes be wholly attributable to endogenous biological factors? Or, alternatively can such differences be attributed to exogenous social factors? Other data also pose difficulties for the biological line of argument. For example, the biological hypothesis cannot easily explain the fairly substantial evidence indicating that those females who do pursue science academic programmes tend, on average, to outperform their male counterparts in the classroom (Decore, 1984, pp. 35-57; Steinkamp and Maehr, 1984, pp. 45). Nor does the biological hypothesis travel well across cultural and national boundaries; it does not readily account for the relatively large proportion of female professional scientists found in Eastern European countries (Kelly, 1982, pp. 497).

The third line of explanation, one that focuses on socialization factors, has gained ground perhaps because of the weaknesses and limited explanatory range of the first two explanations. At the heart of the socialization explanation lies the view that the way young girls are socialized is crucial - that the values that surround them and the expectations of them encourage and cue them to pursue particular educational choices. In turn, those educational choices set the pattern for career paths. Thus the particular cultural milieu provides a structured context of expectations and within that mileu parents, peers and other agents shape in significant ways the nature of appropriate male/female roles (Kelly 1982, pp. 497-500; Ferry and Moore 1982, pp. 27-30). Canadian researchers, like their counterparts elsewhere, argue that girls, unlike boys, are discouraged from, or at least not encouraged to pursue science and that counselling received in junior high and high schools compounds the problem (Fischer, 1982, pp. 63-74). Relatedly, it is suggested that there is stereotyping and a lack of sufficient female role models among scientists (Ellis, 1982: 77-85); and it is contended that there are gender biases in curricula and that teaching methods may convey, subtly, different expectations regarding what girls can achieve. (2)

The socializaton line of inquiry has substantial prima facie appeal. Unlike other approaches it offers a multivariate explanation, one that draws upon a large, well-established literature grounded in social psychology and as such it provides a more comprehensive perspective that can account for cross-cultural variation. But for analysts who see explanation as a first step in the process of redressing the problem of gender imbalances in recruitment to scientific careers, the policy ramifications for the socialization explanation are not very promising. For in providing a socially integrated view of the problem a socially integrated solution is implied, one that calls for a comprehensive shift in social values.

\section{Problem and the Research Strategy}

Despite basic differences in theoretical perspectives, researchers usually concentrate on one particular aspect of the problem, namely the question of why so few females get into the starting blocks of science careers. As a result, much of the 
research effort is directed towards the study of gender differences in science enrolments in the early phases of academic training. However, the small size of the female scientific community is not solely determined by gender differences at the entry point of science training. If that were the case then the number of women in the science professions would be roughly proportional to the number of women graduating from universities with science degrees. But aggregate data suggest not only that there are gender discrepancies in early enrolment in academic science courses but also that there are signficant gender differences in the rates of exit from science (Symmons and Page, 1984, pp. 193, 206). Although, apparently qualified females are more likely to leave the science community than are their male counterparts, we know very little about this aspect of the general problem. The aim of this paper is to examine the nature of this "seepage" at a late decision point, that is, at the time when female senior science undergraduates are making career choices.

There are a number of practical reasons why senior female science undergraduates should be targeted for analysis. Most obviously, this group is strategically significant in the sense that it consists of those women who are the most immediate, serious contenders for science careers. They are the pool from which future role models will be drawn. Any information about why some of these women choose to continue in science and why others do not is potentially useful as it may serve as a policy guide for those interested in pursuing remedies for gender imbalance, remedies that are less ephemeral than a general call for a change in social values and which, though more limited, may have a better chance of success. Unfortunately, much of the available evidence about the "defection" of women from science at this critical juncture tends either to be narrowly focussed on a single group such as engineers (Ellis, 1977, pp. 11-22) or it is anecdotal (Brush, 1985, pp. 11-19; Ferry and Moore, 1982, pp. 27-30; Lonsdale, 1970, pp. 45-59). Though useful, this evidence is limited. It is by expanding the analysis to encompass a broader and more representative segment of the target group that we can move towards a more systematic assessment of the problem.

A second feature of the target group carries implications which can best be appreciated in the context of the preceding discussion of conventional explanations of the problem. Our target group consists of those women with sustained training in science so we can assume that they have overcome such obstacles as "learned helplessness," "math anxiety" and the putative biological and motivational factors. We can assume too that they have been able to deal with those socialization factors that drew others away from science during early confrontations with the science disciplines. By focussing our analysis on this target group we are, in effect, applying a set of approximate controls for those factors that explain why females fail to enter the science academic discipline. Furthermore direct comparisons between this target group and its male cohort helps us to isolate the gender significance of those variables particular to the late stage decision point. This strategy not only allows us to discount generational and lifecycle effects but 
also it enables us to determine whether such variables as social background and performance are relevant to women's career choices in Canada as they are in other national settings (Ferry and Moore 1982, pp. 27).

\section{Data}

This examination of gender differences in career choices of science undergraduates takes place through the secondary analysis of survey questionnaire data that were generated for other purposes.(3) The data are drawn from an 118-item questionnaire completed in $1983-84$ by final year undergraduate university students at nine regionally dispersed Canadian universities, (4) and the data set has a number of features that make it particularly useful for this analysis. First, the research design of the original project called for purposive stratified sampling of the student population with the result that an equal number of males and females were contacted within each of four academic disciplines: science, humanities, social sciences and business/commerce. This strategy produced a matched sub-sample of males and females within the senior undergraduate science community. Second, the questionnaire mail-out was large enough (about 1288 cases) and the response rate strong enough (about 53\%) to yield a sufficient number of cases in our target group ( $N=204$ ) for meaningful analysis. (5) Third, the questionnaire solicited basic background socio-demographic data from respondents as well as evaluations of their academic performance and an open-ended segment of the questionnaire invited respondents to indicate their career goals. The questionnaire then, combines two essential characteristics: it is sufficiently precise for testing hypotheses about gender differences in career goals and, should such differences emerge, it is sufficiently broad to allow for a reasonable search for correlates of those differences.

\section{A. Gender and Career Goals}

We have indicated that in the original study, the data were generated by sampling equal numbers of male and female undergraduates within four broadly defined academic disciplines. Beyond that though, the questionnaires were distributed randomly within each of those broad disciplines so there was, for example, no attempt to match a female mathematics major with a male mathematics major. Consequently we would anticipate that the balance between male and female respondents across the subdisciplines of science to reflect, roughly, the subdisciplinary gender balance within the whole science undergraduate community. Table 1 provides a summary picture of the target group that will be the focus of our analysis and it indicates the gender distribution of science students grouped by discipline within science.

In general, Table 1 provides additional evidence indicating significant differences between males and females in fields of study within science. Engineering students are predominantly male; males outnumber females in the "hard" sciences, 
Table 1: The Gender Distribution of Science Students

$\underline{\text { Gender }}$

Field of Study

Total

Bio-Medical
Sciences

Male

$40.3 \%$

Math/Natural
Sciences

Engineering $\bar{x} \mathscr{x}$

N

Sciences

$58.1 \%$

$79.3 \%$

$57.8 \%$

118

Female

$59.7 \%$

$41.9 \%$

$20.7 \%$

$42.2 \%$

86

(100)

(100)

(100)

(100)

Source: Nevitte-Gibbins Canadian Youth Elite Equality Survey, 1983.

that is, mathematics and the natural sciences; and those females who are in science tend to be concentrated in those areas relating to bio-medical sciences. A more detailed gender breakdown of the bio-medical science category shows that biology is a "female domain" in that they outnumber their male counterparts by a ratio of about $2: 1$, but there is approximate gender parity within the field of medical sciences.

Our concern is not to join others in speculations about whether female students are drawn to academic areas that have to do with "life and nurturing" and males to those fields that deal with "how inanimate things work." Rather, we want to explore the question of whether there are differences between the career aspirations of male and female undergraduates who are alredy within the same sub-disciplines of science academic programmes. The question can be put in the form of the following null hypothesis: if goals are gender neutral then we would expect to find no differences in the career aspirations of male and female respondents within each field of science. The data presented in Table 2 (A through D) address this hypothesis.

Table $2 \mathrm{~A}$ provides an overview of the career choices indicated by male and female science students. The five broad categories indicated there are constructed from responses to the question: "What are your career goals after you get your degree?" Unlike menu-driven questions that present respondents with a choice from a fixed list of options, open-ended questions provide no response cues but as a result, responses can be too ambiguous or general to be useful. In this instance a number of respondents indicated simply that they wanted "to get a job" or "to do something in my field." It is hard to say whether students responding in this way regard their undergraduate degree as a terminal qualification or whether they intend to continue in science. For the purposes of this analysis we regard such 
Table 2: Student Career Goals by Area of Study

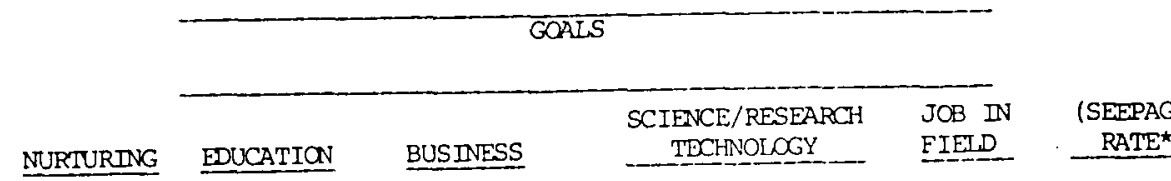

(A) All science students:

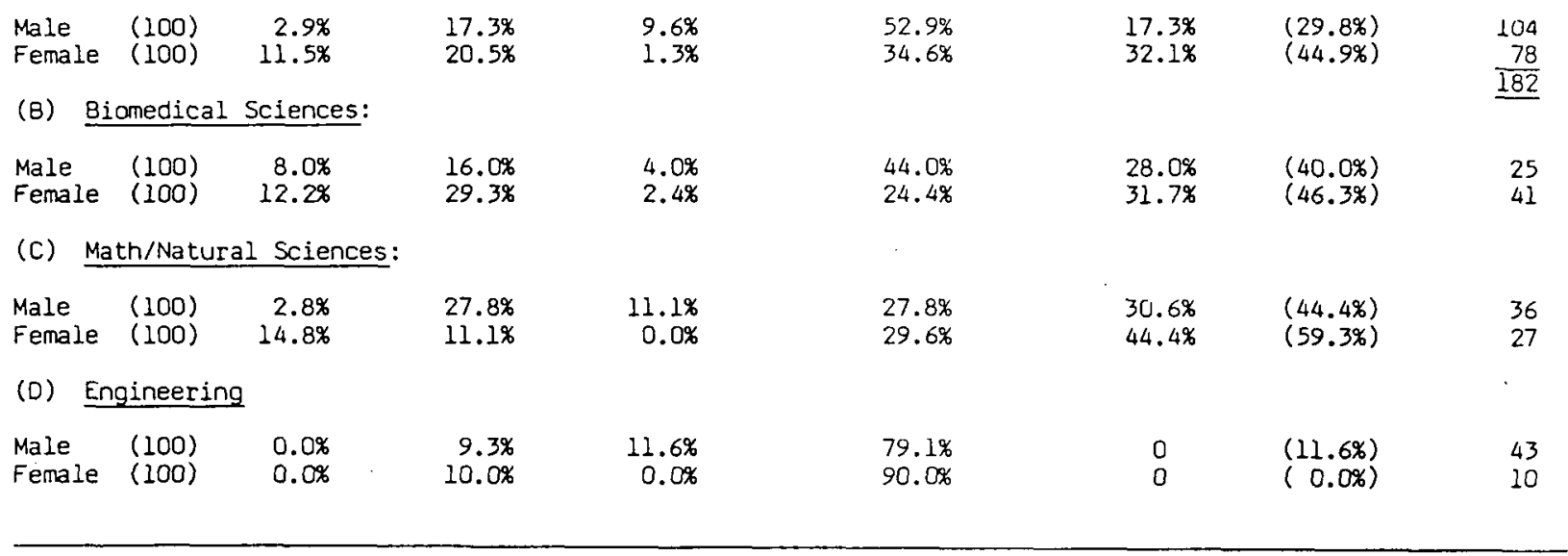

* "Seepage Rate" is calculated as the percentage of the sample that aims to pursue neither further education or Science/Research and technology.

Source: Nevitte-Gibbins Canadian Youth Elite Equality Survey, 1983. 
indeterminate responses as "noise" and we relegate them to the category "job in field." Other responses provide a far more definitive basis for interpretation. Overall, women science students are about four times more likely than their male counterparts to enter such "nurturing" careers as social work or missionary work. Obversely, males are about seven times more likely than their female counterparts to use their science degree as a springboard to "do something in the business world," as one respondent put it.

What is of most interest in Table 2A are the distributions within the remaining new categories: "Further post-graduate education" and "Science, Research and Technology" for it is in those two groups that most unequivocally contain those students who plan to remain in science. Taking these two categories together, the data indicate that male students are less likely than females to defect from the science community at the graduation decision point. The summary calculation of the defection, or seepage, rate expressed in the last column of Table 2 is a conservative estimate for we isolate only those male and female science students who have not explicitly indicated that they intend to pursue a science career path. According to this gross measure, our data show that the overall seepage rate among women science students (44.9\%) is about fifty percent higher than the seepage rate among male science students $(29.8 \%)$ and this difference is a statistically significant one (at $p<.01$ ).

It is by unpackaging the aggregate data summarized in Table $2 \mathrm{~A}$ that we can develop a more detailed picture of how gender correlates with the structure of career choices within the undergraduate science community. Tables $2 \mathrm{~B}, 2 \mathrm{C}$ and 2D break the aggregate data down into three subsamples that correspond to the three academic disciplines within science: Biomedical Science, Math/Natural Science and Engineering and a comparison of three subsamples highlights some interesting interdisciplinary contrasts regarding females career aspirations. Perhaps the most striking data are represented in Table 2D which indicates that the career choices of female engineering undergraduates are atypical in at least two respects. First, none of the female engineers responding to our survey indicated that they planned to pursue a "nurturing" career. Indeed, the overwhelming majority indicated a preference for a science or research and technology career path. Secondly, and perhaps more surprising, is the fact that according to our criteria establishing seepage rate, none of the female engineering undergraduates aim to defect from the science career path. This perfect retention rate is striking in the extreme but these data should be read very cautiously because our sample contains only ten female engineers.

The remaining respondent pools are relatively robust and a comparison of Tables 2B and 2C point up other significant gender differences in career goals, differences that have not been reported elsewhere. We have already pointed out that, unlike other subdisciplines of science, bio-medical sciences cannot be easily characterized as a male dominated domain. Aggregate population statistics on undergraduate enrolments at Canadian universities indicate that of the female students in science the largest proportion are attracted to this field and our sample mirrors that broader trend; female respondents outnumber their male counterparts 
in this subdiscipline. Table 2B indicates that nearly $30 \%$ of the female bio-medical science students plan to further their education in the field; they are about twice as likely as their male counterparts in the field to do so. Of all the male science students those in the bio-medical sciences have the highest seepage rate $(40 \%)$ but the point worth emphasizing is that this seepage rate is still lower than that of their female counterparts in the same field.

These findings contrast rather dramatically with the distribution of career choices betwen male and female students in the Math and Natural Sciences shown in Table $2 \mathrm{C}$. In the bio-medical sciences subsample males were much more likely than females to pursue "science, research or technology" career paths but in the Math/Natural Sciences subdiscipline the proportion following this career path is roughly evenly balanced along gender lines. However, a far larger proportion of this subgroup of male seniors (27.8\%) compared to their female counterparts (only $11.1 \%$ ) reported planning on further post-graduate education and it is this difference that is largely responsible for female's higher seepage rate from the science community.

The initial step in the data analysis provides further support for the general trend that could be inferred from a careful reading of aggregate census data namely, that there are significant gender differences in the recruitment of senior science undergraduates to the science community. A more detailed examination of individual level data though enables us to illustrate the significant subdisciplinary variation in these seepage rates for Canadian science students. In addition, we can identify two gender based trends with respect to the direction of seepage: (1) with the exception of engineering students, women are consistently more likely than men to leave science for "nurturing" careers, and (2) in all instances, across all subdisciplines within science, female students are systematically less likely to regard "business" as an attractive career option.

An overview of the subdisciplinary variations in seepage rates throws into bold relief the atypical structure of the career goals of engineering students, both male and female. We have emphasized the need for caution in drawing firm conclusions on the basis of such a limited sample of female engineering students but evidence of unusually low seepage rates in this subsample remains an intriguing finding nonetheless. We could speculate that in pursuing an undergraduate degree in engineering these students, more unequivocally than their counterparts in other areas of science, have already crossed the threshold of a professional career path, a career path that provides unusually clear expectations about career rewards and professional norms and which fully engages students in reinforcing anticipatory socialization. But to confirm such an analysis would call for other data, data that could both identify engineering bound students at an earlier decision point and data that could probe the motivations of these candidates.

\section{B. Are Canadian Women Science Students Different?}

While our data do not permit us to delve into the specific incentives that encourage women to pursue science, nevertheless we are in a position to search for background factors that may be unique to such a group. To conduct such a search 
we followed standard exploratory scanning procedures: the science sample was divided according to gender and the two groups were then compared along an array of approximately twenty standard social, cultural, economic and demographic indicators. That data sweep revealed statistically significant differences between male and female science students with respect to father's occupation. Our principal finding in this regard is that female science undergraduates are significantly more likely than their male counterparts $(p<.05)$ to have fathers in scientific and technological occupations. Beyond that, what is clear from the more detailed breakdown of our data presented in Tables 3a through 3d, is the extent to which father's occupation operates as a structuring variable that not only differentiates female from male science students but it also clearly differentiates female science students from females in other academic disciplines.

Furthermore, standard statistical tests indicate that father's occupation is a stronger correlate of daughter's degree programme than is father's education. Moreover when biology students are excluded from the female science sample, the results are even more striking. A comparison of Tables $3 \mathrm{c}$ and $3 \mathrm{~d}$ shows that father's occupation is a background variable that decisively distinguishes female students in the "hard sciences" from females in the social sciences and in this instance as well, occupation correlates more strongly than does father's education.

We find no Canadian literature reporting such evidence but reports of similar findings in Britain speculate that it is the encouragement of fathers, along with teachers, that is significant to women's academic and career choices. The precise line of reasoning that links father's occupation to female students' academic and career aspirations, however, is neither a particularly clear nor compelling one. The question of why father's occupation and "encouragement" should be more relevant than say, mother's occupation, level of education or "encouragement" is not an issue that has been either systematically addressed or persuasively answered. Our attempt to explore this issue through a comparison of mother's and father's occupation yielded too few instances of working mothers to pursue a meaningful analysis. This finding is itself significant because it suggests the importance of a generation gap. Presumably, as more mothers routinely enter the workforce and pursue sustained careers, such a comparison would be an increasingly meaningful one. But is is in the context of the absence of dual careers that the occupational experience of fathers becomes especially meaningful; it becomes the only conduit for precise images and expectations regarding career paths. In this instance we can speculate that fathers who hold scientific and technological careers in a sense, demystify science for their progeny both male and female, but especially female. At bottom, such a line of speculation borrows from the socialization argument and suggests that familial contextual factors and role models are relevant at career decision points as well as during earlier decision points that relate to selecting the field of academic study.

\section{Does Performance Make a Difference?}

The chance of achieving high-flying scientific careers, of course, is not solely determined by background socio-structural factors such as father's occupation; it 
42 N. Nevitte, R. Gibbins and P.W. Codding

Table 3: Father's Occupation and Education: Female Students

(A) Father's Occupation For Female Students in Science and Social Science

Female Students Degree Programme
Father's

Occupation

Science/Technology

White Collar

Blue Collar

\begin{tabular}{lcc} 
Science & $\begin{array}{l}\text { Social } \\
\text { Science }\end{array}$ & $\overline{\mathrm{X}} \%$ \\
$28.0 \%$ & $14.3 \%$ & $20.1 \%$ \\
$57.4 \%$ & $57.1 \%$ & $57.2 \%$ \\
$14.6 \%$ & $28.6 \%$ & $22.7 \%$ \\
\hline$(100)$ & $(100)$ & $(100)$ \\
\hline & & $N=194$
\end{tabular}

CHI squared significant at $p<.05$

(B) Father's Education for Female Students in Science and Social Science

\begin{tabular}{lccc}
$\begin{array}{l}\text { Father's } \\
\text { Highest Education }\end{array}$ & Science & $\begin{array}{l}\text { Social } \\
\text { Science }\end{array}$ & $\overline{\mathrm{X}} \%$ \\
$\begin{array}{l}\text { Some High School } \\
\text { or less }\end{array}$ & $22.0 \%$ & $38.4 \%$ & $31.4 \%$ \\
High School Grad & $26.0 \%$ & $19.2 \%$ & $22.1 \%$ \\
$\begin{array}{l}\text { Some University or } \\
\text { other Post-Secondary }\end{array}$ & $26.0 \%$ & $27.3 \%$ & $26.7 \%$ \\
$\begin{array}{l}\text { University Grad or } \\
\text { Post-Grad }\end{array}$ & $26.0 \%$ & $15.1 \%$ & $19.8 \%$ \\
\cline { 2 - 4 } & $(100)$ & $(100)$ & $(100)$ \\
\hline
\end{tabular}

CHI squared not significant at $p<.05$

depends, at least in part, upon how well students perform academically. Available evidence suggests that generally, within the academic setting, women science students perform at least as well, if not better, than their male counterparts. The very best university science graduates are an especially important national resource for they constitute the critical pool from which tomorrow's senior scientists will be drawn. If any group is likely to lead the way for women in science and to provide role models for the next generation of women scientists, it will be this one. But the chances of breaking the current gender mold of the senior science community hinges upon the career choices of the very best female science 
(C) Father's Occupation for Female Students in Non-Biological Science and Social Science

\section{Female Students Degree Programme}

Father's Occupation

Science/Technology White Collar Blue Collar

\begin{tabular}{ccc}
$\begin{array}{c}\text { Non-Biological } \\
\text { Science }\end{array}$ & $\begin{array}{l}\text { Social } \\
\text { Science }\end{array}$ & $\bar{X} \%$ \\
$26.8 \%$ & $13.2 \%$ & $17.5 \%$ \\
$63.4 \%$ & $56.0 \%$ & $58.3 \%$ \\
$9.8 \%$ & $30.8 \%$ & $24.2 \%$ \\
\hline$(100)$ & $(100)$ & $(100)$ \\
\hline & & $N=132$
\end{tabular}

CHI squared significant at $p<.01$ (D) Father's Education for Female Students in Non-Biological Sciences and

\begin{tabular}{lccc}
$\begin{array}{l}\text { Father's } \\
\text { Highest Education }\end{array}$ & $\begin{array}{c}\text { Non-Biological } \\
\text { Science }\end{array}$ & $\begin{array}{l}\text { Social } \\
\text { Science }\end{array}$ & $\bar{X} \%$ \\
$\begin{array}{l}\text { Some High School } \\
\text { Or less }\end{array}$ & $13.9 \%$ & $\begin{array}{l}40.1 \% \\
19.5 \%\end{array}$ & $\begin{array}{l}32.3 \% \\
22.0 \%\end{array}$ \\
High School Grad & $27.8 \%$ & $26.8 \%$ & $27.1 \%$ \\
$\begin{array}{l}\text { Some University or } \\
\text { other Post-Secondary }\end{array}$ & $27.8 \%$ & $13.4 \%$ & $18.6 \%$ \\
$\begin{array}{l}\text { University Grad or } \\
\text { Post-Grad }\end{array}$ & $30.5 \%$ & $(100)$ & $(100)$ \\
\cline { 2 - 4 } & $(100)$ & & $\mathrm{N}=100$
\end{tabular}

CHI squared not significant at $p<.05$

Source: Nevitte-Gibbins Canadian Youth Elite Equality Survey, 1983.

students. In this context the question to which we now turn becomes a crucial one: Does the level of academic performance make a difference with respect to career goals?

In reviewing the general career goals of the entire student science sample we indicated earlier that the seepage rate for female science students exceeded that of their male conterparts (Table 2). Table 4 elaborates these data by dividing the target group according to self-reported academic performance. (6) 
Table 4: Career Goals and Academic Performance

(a) "Top" Academic Performers:

\begin{tabular}{|c|c|c|c|c|c|c|c|}
\hline \multirow{2}{*}{\multicolumn{2}{|c|}{ Gender (N) }} & \multicolumn{5}{|c|}{ Career Goals } & \multirow[b]{2}{*}{$\begin{array}{l}\text { Seepage } \\
\text { Rate }\end{array}$} \\
\hline & & Nurturing & $\begin{array}{l}\text { Further } \\
\text { Education }\end{array}$ & Business & $\begin{array}{l}\text { Science/Research } \\
\text { Technology } \\
\end{array}$ & $\begin{array}{l}\text { Job in } \\
\text { Field }\end{array}$ & \\
\hline Male & (70) & $1.4 \%$ & $18.6 \%$ & $8.6 \%$ & $51.4 \%$ & $20.0 \%$ & $30.0 \%$ \\
\hline Female & (44) & $15.9 \%$ & $11.4 \%$ & $0.0 \%$ & $43.2 \%$ & $29.5 \%$ & $45.4 \%$ \\
\hline
\end{tabular}

(b) "Average" Academic Performers:

\begin{tabular}{|c|c|c|c|c|c|c|c|}
\hline Gender & (N) & & Further & & Science/Research & Job in & Seepage \\
\hline & & Nurturing & Education & Business & Technology & Field & Rate \\
\hline Male & (33) & $6.1 \%$ & & $12.1 \%$ & $57.6 \%$ & $12.1 \%$ & $30.3 \%$ \\
\hline Female & (34) & $2.9 \%$ & $32.4 \%$ & $5.9 \%$ & $23.5 \%$ & $35.3 \%$ & $38.0 \%$ \\
\hline
\end{tabular}

Source: Nevitte-Gibbins Canadian Youth Elite Equality Survey, 1983

There are several significant findings that emerge from this breakdown of the data. First, a comparison of Tables $4 a$ and $4 b$ indicates that the general finding that males have a lower seepage rate than females is a trend that holds true regardless of academic performance. But what is striking from a comparison of the "seepage rate" marginals is the finding that there are significant differences in the seepage rates for female science students. Given that performance is an essential ingredient of career success for senior scientists we might expect that the very best female students would, ceteris paribus, be more likely to plan on staying within the science community. The evidence presented in Table 4 however, contradicts such an expectation. The data show that the very best female science students are more likely than their "average" performing counterparts to defect from science and in fact, it is top academic peforming female science students that report the highest seepage rate of any of the groups under consideration. A more detailed picture of the structure of that "seepage" can be fleshed out by a comparison of the career goals of all four groups.

The impact of performance on the career goals of male science students can be summarized fairly easily. Top male performers are less likely than average performers to turn to nurturing or business careers. Instead, they are more likely, about fifty percent more likely, to indicate that further education is an immediate career goal. If this pattern of career goals is regarded as normal then the impact of performance on the goals of female science students would have to be regarded as perverse for the prevailing pattern for their female counterparts is almost precisely the opposite. Although our sample is fairly small, the best female science students 
Table 5: Students Continuing Education

Field of
Study

\begin{tabular}{lll} 
& Male & Female \\
& $16.9 \%$ & $23.2 \%$ \\
Social science & $17.3 \%$ & $20.5 \%$ \\
Science & $17.7 \%$ & $10.8 \%$ \\
$\begin{array}{l}\text { Non-biological } \\
\text { science }\end{array}$ & $17.3 \%$ & $18.16 \%$ \\
\hline $\bar{X} \%$ & & \\
\hline
\end{tabular}

Source: Nevitte-Gibbins Canadian Youth Elite Equality Survey, 1983.

are about five times more likely than average performers to seek "nurturing" careers and perhaps most astonishingly, average performers are about three times more likely than top performers to plan on pursuing further post-graduate education. The best performers are more likely to see jobs in science, research and technology as a career option but none view business as an attractive career goal.

These findings are easier to describe than to explain. We are not suggesting that futher post-graduate education should be a domain limited to only the very best students. But if further post-graduate education is a necessary stepping stone in the career paths of senior scientists, then from the point of view of maximizing the chances of getting the very best scientific talent into the science community, the proportion of superior female science students aiming to pursue that career path is alarmingly low. The scope of that loss is most serious for those female science students in the non-biological science according to the data presented in Table 5.

The most telling tale that emeges from this exploratory analysis is the one that reveals itself by indirection. Academic ability alone is not a sufficient condition for propelling talented science students towards full-fledged science careers; it is the combination of ability and aspiration that is crucial. These data unequivocally indicate that the most able female science students are significantly less likely than males to use their early success in science as a launching pad for careers within the science community. The clear implication is that the problem of the shortage of female scientists is not just a matter of early socialization, "math anxiety" or "learned helplessness;" the problem is also that the most able female science students, students who have already overcome the legion of real or imagined obstacles to entering science, still do not see science careers on the whole, as an attractive career option. 


\section{CONCLUSIONS:}

Much of the research aimed at explaining why there are so few female scientists in Canada has focussed on gender differentials in science enrolments during the early stages of academic training. We have argued that the pre-occupation with that focus may have deflected attention away from another significant aspect of the problem, namely, the "seepage" of women from science at a later decision-point. The aim of this paper has been to explore the scope and nature of this seepage through the secondary analysis of a gender stratified sample of senior undergraduate students at nine Canadian universities. In doing so, three avenues of investigation were undertaken: (1) an assessment of gender differentials in the career aspirations of science students; (2) a search for social, economic and cultural correlates that distinguish female science students from their male counterparts; and (3) an evaluation of the impact of academic performance on career goals. First, our data indicate that there are substantial and statistically significant differences between male and female students with respect to career aspirations. Second, the data scan of socio-demographic background variables revealed that father's occupation consistently distinguished female science students from their male counterparts. Finally, the data show that academic performance does indeed have a significant impact on the career goals of science students. That impact, however, is counter-intuitive for all of the groups under consideration: it was the very best female science students that were found to be least likely to plan further post-graduate education.

Had our research findings indicated no gender differences in the seepage rates from the scientific community at the last decision-point then we could reasonably infer that the problem of low numbers of women in science is rooted in the early socialization processes. Given the gradual increases in female enrolments in high school science courses over the last two decades we could have concluded, optimistically perhaps, that the solution to the problem was already in motion and that gender equality in this respect would be "just a matter of time." However, our findings provide no grounds whatsoever for such optimism. The quasi-experimental design approach to the research problem, that is, the focus on the matched gender sample of students already in science, is an approach that minimizes the force of the socialization argument that is common in research literature in this area. But the general lack of socio-demographic correlates may also suggest that the early stages in the learning/socialization process may not be all that important for the target group studied here. If the socialization argument is set aside, then the central question that emerges is: why do women, especially the top performing women, defect from science at a greater rate than their male counterparts? That is the question that must be addressed by future research. This paper directs attention to the critical nature of the late stage decision-point and in that respect it establishes the contours of the issue but our data do not allow us to dig beneath the surface of responses about career goals. Nevertheless, in establishing the contours of the problem and in focussing on the central question we can suggest the kind of research strategy that could inform a policy response to the problem. 
We suggest that a least three sorts of research questions can be usefully pursued. First, what factors encourage women to go into science? What expectations do they carry with them regarding careers within science? And, do those expectations shift during the course of their science training? Second, what are the operating incentive structures of female science students at the point of making career choices? And, what factors are decisive in encouraging some to choose a science career path? Third, for established female scientists, what factors, retrospectively, were critical in making their career choices? And, why were those factors critical? It is by addressing these issues that we can gain further insight into the importance of father's occupation and whether, for instance, gender disparities in science can be explained by voluntary career shifts, lack of role models, or such factors as the anticipation of blocked mobility.

Of course, whether the issue of gender imbalance within the science community is "a problem" at all is a matter of perspective. We have suggested that it can be seen as a problem on at least two counts. There is the general social question of gender equity and the increased marginalization of women in a work force that demands increasingly scientific literacy. But quite aside from the social dimension of gender sympathies, there is also the question of how to increase the supply of an important national resource. If only about 10 percent of the best female students in the "hard" sciences is considering post-graduate education in science, then notwithstanding our gender sympathies or politics, it is clear that we are underutilizing scientific talent. From this perspective alone, it would be short-sighted of policy makers to ignore half of the potential resource pool. Regardless of which perspective is taken, any proposed policy response has to rest upon a much more focussed, systematic and substantial understanding of the dynamics of late point career decision making.

\section{NOTES*}

An earlier version of this paper was presented at the Annual Meetings of the Chemical Institute of Canada, Laval University, Quebec City, June, 1987.

1. A recent Statistics Canada report, Who are the Professional Women. (1987: Ottawa) indicates that the number of female civil engineers has increased threefold in the last 10 years - from $1.1 \%$ to $3.3 \%$, and that this constitutes the highest representation of women in any of the eight categories of the engineering profession. Of all the 46 professional groups considered, 34 are "male dominated" and 5 are "female dominated" - all five are related to teaching.

2. Steinkamp and Maehr report that girls are both more negative about the relationship between themselves and science and that they are less likely to express interest in science through active involvement with science related extra-curricular activities (1984, p. 45).

3. These data were collected by Roger Gibbins and Neil Nevitte; they constitute the Canadian segment of the Cross-National Equality Project, a seven country study of the values of selected elites in Western industrialized societies. The original project was designed under the direction of Sidney Verba, Department of Government, Harvard University.

4. These include: Memorial, Dalhousie, Montreal, Laval, Toronto, Queen's, Wilfrid Laurier, Calgary and British Columbia. Students at the University of Montreal and Laval University were sent a french language questionnaire. The usual precautions relating to translation and back-translation were taken and both the English and French versions of the questionnaire were field tested.

5. Standard reliability tests indicate no systematic biases within the respondent pool. 
6. Respondents were asked: "Do you rate your academic performance as, Above Average? Average? or, Below Average? ". Self-reported performance evaluation are far from ideal. But, we have no grounds for suspecting that women are more likely than men to misrepresent their performance. The normal practice is to assume that any sources of error will be random rather than systematic. If error is systematic then the sociological evidence regarding gender and such issues as self-esteem would lead us to believe that males are more likely than females to overestimate their performance. Further, if that is the case with our data, then by assuming random error in self-reported academic performance we are adopting a conservative strategy. We assume random error.

*We would like to thank Janet Harvie for her assistance with the data analysis and the Journal's referees who made insightful comments upon an earlier draft.

\section{REFERENCES}

Brush, S.G. (1985). Women in Physical Science. The Physical Teacher, 23 (1), 11-19.

Decore, A.M. (1981). Vive la Difference: A comparison of Male Female Academic Performance. Canadian Journal of Higher Education, 14 (3), 35-58.

Devereaux, M.S. and Rechnitzer E. (1980). Higher Education - Hired? Sex Differences in Employment Characteristics of 1976 Post-Secondary Graduates. Ottawa: Women's Bureau, Statistics Canada and Labour Canada, Supply and Services Canada, 37, Table 3.

Ellis, D. (1982). Rite Models, Career Expectations and Counseling. In Who Turns the Wheel? Ottawa, Science Council of Canada: 75-85.

Ellis, D. (1977). A Study of a Cohort of Ontario Engineering Students from 1955 to 1976. Canadian Journal of Education, 2 (4), 11-22.

Ferry, G. and Moore J. (1982). True Confessions of Women in Science, New Scientist 95 (1312), 27-30.

Fischer, L. (1982). Science and the Environment of Young Girls. In Who Turns The Wheel? Ottawa: Science Council of Canada: 61-74.

Hyde, J. (1981). How Large are Cognitive Gender Differences? American Psychologist, 36 (8), 892-901.

Kelly, A. "Why Girls Don't Do Science". New Scientist, 94, (1306), 497-500.

Kimbell, M.M. (1982). Sex Differences in Intellectual Ability. In Who Turns the Wheel? Ottawa: Science Council of Canada: 45--60.

Maccoby, E. and Jacklin, C. (1974). The Psychology of Sex Differences. Stanford, CA: Stanford University Press.

Proceedings (1982). Who Turns the Wheel? Workshop on the Science Education of Women. Ottawa: Science Council of Canada, 7-8.

Scott, J. (1982). Is There A Problem? In Who Turns The Wheel? Workshop on the Science Education of Women. Ottawa: Science Council of Canada: 21-44.

Sex Differences of 1976 Post-Secondary Graduates. (1980). Statistics Canada and Labour Canada.

Steinkamp, M.W. and Maehr M.L. (1986). Gender Differences in Motivational Orientations Toward Achievement in School Science: A Quantitative Synthesis. American Educational Research Journal, 21 (1), 39-59.

Struik, R.R., and Flexer R.J. (1984). Sex Differences in Mathematical Achievement: Adding Data to the Debate. International Journal of Women's Studies 7 (714): 336-342.

Symmons, T.H.B. and Page, T.E. (1984). Some Questions of Balance: Human Resources, Higher Education and Canadian Studies. To Know Ourselves. Report of the Royal Commission on Canadian Studies Vol. 3. Ottawa: Association of Universities and Colleges of Canada. 